\title{
Erratum to: Scale-Dependent Feedbacks Between Patch Size and Plant Reproduction in Desert Grassland
}

\author{
Lauren N. Svejcar, ${ }^{1,2,4}$ Brandon T. Bestelmeyer, ${ }^{1 *}$ Michael C. Duniway, ${ }^{1,3}$ \\ and Darren K. James ${ }^{1}$
}

\footnotetext{
${ }^{1}$ USDA-ARS Jornada Experimental Range and Jornada Basin LTER, MSC 3JER, Box 30003, Las Cruces, New Mexico 88003, USA;

${ }^{2}$ Department of Plant and Environmental Sciences, New Mexico State University, Las Cruces, New Mexico 88003, USA; ${ }^{3}$ U.S

Geological Survey Southwest Biological Science Center, 2290 SW Resource Blvd, Moab, Utah 84532, USA; ${ }^{4}$ Present address: Department of Animal and Range Science, New Mexico State University, Las Cruces, New Mexico 88003, USA
}

\section{ERRATUM TO: ECOSYSTEMS (2015) 18: 146-153 \\ DOI: $10.1007 / \mathrm{s} 10021-014-9818-9$}

In the published manuscript, a sentence pertaining to a portion of the analysis that was deleted at the behest of reviewers was erroneously left at the end of the results. On page 150, right column, the second-to last sentence: "Over the April-October $2011 \mathrm{spring} /$ summer period, there was an increase in RR for $\mathrm{S}$ while decreases were observed in the other patch classes (contrast of change in $\mathrm{S} R \mathrm{R}$ vs. all others over that period $=3.5 \pm 0.6 ; \mathrm{F}=34.50 ; \mathrm{P}<$ $0.0001)$. This pattern was not observed for other variables." appears duplicative of the previous result and should have been removed. 